\title{
DYNAMICS OF THE LAW DOME ICE CAP, ANTARCTICA, AS FOUND FROM BORE-HOLE MEASUREMENTS
}

\author{
by
}

\author{
D.M. Etheridge
}

(Australian Antarctic Division, Channel Highway, Kingston, Tasmania 7050, Australia)

\section{ABSTRACT}

The internal dynamics of the Law Dome ice cap have been investigated by measuring the deformation of three bore holes located on an approximate flow line. Bore holes $\mathrm{BHCl}$ ( $300 \mathrm{~m}$ deep) and $\mathrm{BHC} 2(344 \mathrm{~m})$ were drilled in the coastal area to within several metres of bedrock and BHQ $(418 \mathrm{~m})$ was drilled about half-way towards the dome centre to about $50 \%$ of the ice thickness. Detailed measurements of orientation (inclination and azimuth), diameter, and temperature were taken through each bore hole over a 1 year span for $\mathrm{BHCl}$ and $\mathrm{BHC} 2$ and a 10 year span for BHQ. The orientation data were reduced to obtain $\partial u / \partial z$, a measure of the shear strain-rate. Changes in the depth of features located by bore-hole diameter measurements were used to obtain vertical velocity profiles. Other measurements discussed are temperatures, oxygen isotopes, crystal structure, surface velocities, and surface and bedrock topography.

At the coastal sites, the $\partial u / \partial z$ profiles show two maxima in the lower third of the ice sheet. Flow due to the measured deformation accounts for about $55 \%$ of the surface velocity, the remainder being due to deformation and sliding in the basal zone. The vertical velocity profiles show mostly firn compression. The deeper $\partial u / \partial z$ maximum occurs in ice from the Wisconsin period which appears to deform more rapidly than the Holocene ice immediately above. The upper $\partial u / \partial z$ maximum may be related to the stress history of the ice, which can also explain the presence of significant shear strain and crystal-fabric development at only half the ice thickness at the BHQ site.

\section{INTRODUCTION}

The Law Dome ice cap adjoins the East Antarctic ice sheet. It is about $200 \mathrm{~km}$ in diameter and about $1200 \mathrm{~m}$ thick at the centre. Its internal flow and structure have been investigated by drilling along an approximate flow line from the summit to Cape Folger, analysing the cores, and suveying the bore holes. A profile of this line showing the bore-hole locations is given in Figure 1. A great deal of background information exists on the area including borehole and ice-core studies by Matsuda and others (1976), Russell-Head and Budd (1979), and Thwaites and others (1984), surveys by Pfitzner (1980), and stratigraphic studies by Xie (1984) and Young and others (1985). Matsuda and others (1976) analysed the BHA ice core and found two regions in the lower half of the ice cap with small, well-aligned crystals and strong bubble elongation that suggested a pattern of shear strain. No bore-hole deformation measurements were taken. Russell-Head and Budd (1979) measured bore-hole deformation and ice-core properties at nearby BHF and found large shear strainrates at depths corresponding to the upper region in BHA in ice also with small crystals and single-pole orientation fabrics. Measurements of $\delta^{18} \mathrm{O}$ (Budd and Morgan, 1977) showed that ice at the bottom of BHA and BHF was formed during the Wisconsin period. Unfortunately, the BHF bore-hole measurements could not be taken in this bottom layer due to bore-hole closure and the dynamics of the Wisconsin ice remained unknown.

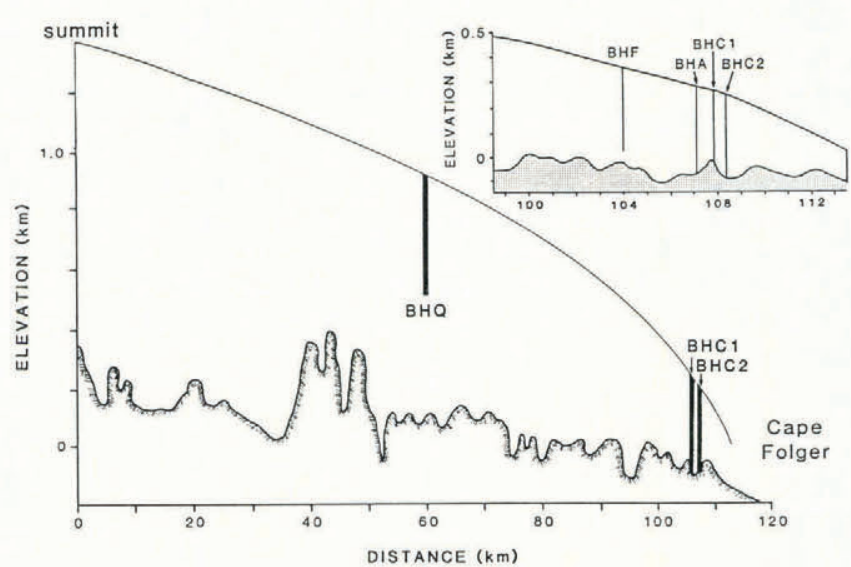

Fig. 1. Cross-section of Law Dome from the summit to Cape Folger, showing the bore-hole sites. Inset is the Cape Folger area in more detail (adapted from Budd and Rowden-Rich, 1985), showing also the position of the older bore-hole sites BHA and BHF.

The data analysed here are from surveys of two bore holes, $\mathrm{BHCl}$ and $\mathrm{BHC} 2$, that were drilled to within several metres of bedrock in the Cape Folger area, and from bore hole BHQ that penetrated $50 \%$ of the ice thickness half-way towards the dome's summit. BHCl was drilled above a bedrock rise about $4 \mathrm{~km}$ down-stream from $\mathrm{BHF}$, and $\mathrm{BHC} 2$ was drilled above a bedrock hollow $350 \mathrm{~m}$ further down-stream. Several complete bore-hole surveys during 1 year allowed the ice dynamics from surface to bedrock, including the Wisconsin ice, to be analysed. BHQ was also drilled in an area above rough bedrock with a large bedrock rise $12 \mathrm{~km}$ approximately up-stream. Re-surveys of BHQ over a 10 year span were used to analyse the dynamics in this area of the ice cap.

\section{BORE-HOLE DRILLING AND SURVEY TECHNIQUES}

All the bore holes discussed here were drilled using a modified CRREL thermal drill similar to that described by Bird and Ballantyne (1971). It drilled a $170 \mathrm{~mm}$ diameter hole, collecting a $120 \mathrm{~mm}$ diameter core. The holes were filled to the firn-ice transition depth with a mixture of kerosene and tetra-chloroethylene. All the cores were retained and have since been analysed for $\delta^{18} \mathrm{O}$ and crystal structure.

The bore holes were surveyed for temperature, diameter, and orientation (inclination and azimuth). Temperature was measured with a $100 \Omega$ platinum sensor and a Leeds and Northrup 8078 resistance bridge. The dry firn section of each hole was measured with the sensor pressed against the wall. The fluid-filled section was measured with the sensor suspended in the fluid. Both types of temperature measurement had an accuracy of $0.025^{\circ} \mathrm{C}$.

Diameter was measured with a three-leg calliper, with an accuracy of $1 \mathrm{~mm}$. Several continuous profiles were measured for each survey. 
Bore-hole orientations were measured with a $2 \mathrm{~m}$ long instrument fitted with guides at each end to keep it concentric with the hole. The instrument housed a pair of orthogonally mounted Schaevitz LSRP inclinometers and an Aanderaa 1248 electronic compass. A Pajari mechanical bore-hole surveying instrument was also occasionally used as a check. The in-situ accuracies of the inclination and azimuth measurements were $0.08^{\circ}$ and $10^{\circ}$, respectively. This accuracy constitutes the combined effects of the inherent sensor accuracy and the instrument-alignment accuracy. To reduce systematic errors, such as the effect of the winch cable deflecting the alignment of the instrument and asymmetries in the centralizing guides, multiple traverses of the bore holes were performed.

Depth was measured by electronically counting the rotation of the winch-cable pulley. Depth measurement accuracy was better than $0.05 \mathrm{~m}$.

\section{THE DATA SETS}

Bore hole $\mathrm{BHCl}$ was drilled in December 1981 to a depth of $300.2 \mathrm{~m}$, where bedrock material and bore-hole closure prevented further penetration. Ice-radar soundings showed that bedrock was no more than $10 \mathrm{~m}$ below. A survey of temperature and diameter was immediately performed before the hole was filled with fluid to the firn-ice transition depth of $31.5 \mathrm{~m}$. Orientations were then measured at $2 \mathrm{~m}$ depth increments. A second survey was performed in June 1982, although diameter was not measured and compass problems created some large azimuth errors. A third survey in December 1982 and January 1983 successfully measured temperatures every $10 \mathrm{~m}$, orientations every $2 \mathrm{~m}$, and diameter profiles.

In January 1982, BHC2 was drilled to a depth of $344.3 \mathrm{~m}$, where an inclined band of bedrock material was encountered and closure rates of $2 \mathrm{~mm} / \mathrm{h}$ prevented further penetration. The ice thickness was no more than $358 \mathrm{~m}$. Dry bore-hole temperatures and diameters were taken before fluid filling to a depth of $34 \mathrm{~m}$. Orientations were then measured at $2 \mathrm{~m}$ depth increments. The June 1982 survey could not penetrate a blockage at $297.5 \mathrm{~m}$ depth. This was cleared before a survey in January 1983 but further constrictions were found below. Although a depth of $340 \mathrm{~m}$ was reached with a $20 \mathrm{~mm}$ diameter temperature instrument, a $50 \mathrm{~mm}$ diameter orientation instrument would not pass $325 \mathrm{~m}$ and the standard $100 \mathrm{~mm}$ diameter instruments would not pass below $320 \mathrm{~m}$. A fourth survey in February 1987 stopped at a blockage at $37 \mathrm{~m}$.

BHQ was drilled and surveyed to $418 \mathrm{~m}$ in May and June of 1977. The ice thickness was $790 \mathrm{~m}$ but varied by as much as $80 \mathrm{~m}$ within $1 \mathrm{~km}$ of the bore hole. The bore hole was filled with fluid to a depth of $42.6 \mathrm{~m}$. Temperature and diameter measurements were taken and orientations were measured every $10 \mathrm{~m}$ depth. A second survey in 1979 failed to provide accurate results. Surveys in January 1983 and February 1987 successfully provided temperatures at $10 \mathrm{~m}$ intervals, continuous diameter profiles, and orientation measurements every $2 \mathrm{~m}$.

\section{DATA ANALYSIS}

The following analyses use a right-handed coordinate system with the origin at the top of the bore hole, the $x$-axis horizontally in the direction of the surface flow, the $y$-axis horizontal and orthogonal to $x$, and the $z$-axis positive vertically upwards, such that depth is $-z$. Velocities along these axes are $u, v$, and $w$, respectively.

\section{Horizontal deformation}

Each bore-hole orientation survey set consisted of values of depth, inclination $I$ (degrees from vertical), and azimuth $A$ (degrees clockwise from true north) at each measurement point, $n$. The position of each point was calculated in polar coordinates, i.e. the distance and bearing from the vertical line passing through the bottom of the hole. The difference between two coordinates, divided by the time interval between each survey then gave the velocity vector, $\boldsymbol{V}$, of each point $n$, relative to the bottom of the hole. (The survey set with the greater number of data points was interpolated to give $I$ and $A$ values at the depths corresponding to the measurement points in the other set.) The difference between $\boldsymbol{V}$ for two neighbouring points, divided by the depth between them, gave the vector velocity gradient, $\partial V / \partial z$. The component of $\partial V / \partial z$ resolved in the surface-flow direction is thus $\partial u / \partial z$. This analysis omitted the other terms that can contribute to bore-hole tilt, i.e. $w \partial i_{x} / \partial z, i_{y} \partial u / \partial y$, and $i_{x}(\partial u / \partial x-\partial w / \partial z)$, where $i_{x}$ and $i_{y}$ are components of $I$ along $x$ and $y$ (Raymond, 1971, equation (9)). Calculations based on the bore-hole and surface-survey data showed that all these terms were more than one order of magnitude smaller than $\partial u / \partial z$. An alternative analysis of the inclination and azimuth data, similar to that used by Dahl-Jensen and Gundestrup (1987) showed negligible differences between the two sets of results obtained for $\partial u / \partial z$.

The derived profiles of $\boldsymbol{V}$ and $\partial u / \partial z$ for each of the bore holes are given in Figures 2(a) and (b), 3(a) and (b), and $4(\mathrm{a})$ and (b). The profiles were smoothed by running an 11 point (equal to about $10 \mathrm{~m}$ ) mean through the combined results of both survey intervals.

Before smoothing, the $\partial u / \partial z$ profiles displayed a standard error of $0.005 \mathrm{a}^{-1}$ in the top half of $\mathrm{BHCl}$ and $\mathrm{BHC2}$, increasing to about $0.01 \mathrm{a}^{-1}$ towards the bottom. For $\mathrm{BHQ}$, the standard error ranged from 0.001 to $0.002 \mathrm{a}^{-1}$. The error in the magnitude of $\boldsymbol{V}$ at the surface was $0.4 \mathrm{~m} \mathrm{a}^{-1}$ for $\mathrm{BHC} 1$ and $\mathrm{BHC} 2$, and $0.15 \mathrm{~m} \mathrm{a}^{-1}$ for BHQ. These values were consistent with the in-situ accuracy of the inclination and azimuth measurements given earlier.

\section{Vertical deformation}

Profiles of bore-hole diameter versus depth revealed recognizable features which were produced by the thermal drilling process approximately every $2 \mathrm{~m}$. By accurately measuring the change in depth of these features with time, the vertical velocity profile of the ice sheet could be found.

Several corrections were first made to the measurements. The actual measurement was of the length $S$ down the bore hole to each feature. The value of $S$ for each point was averaged for the two or three diameter profiles taken during each survey. To relate all $S$ values to a common origin, the topmost feature (typically above a depth of $2 \mathrm{~m}$ ) was used as a zero reference. The same logging instrument, cable, and depth counter were used for each survey. Since the holes were never vertical, it was necessary to convert the value of $S$ for each point to a vertical distance $z$. The size of this conversion was different for each survey because the bore hole deformed (due to shear) and lengthened. The conversion utilized the inclination data for each survey where

$$
z_{\mathrm{m}}=s_{1} \cos I_{1}+s_{2} \cos I_{2}+\ldots s_{\mathrm{m}} \cos I_{\mathrm{m}}
$$

is the vertical distance to feature $\mathrm{m}, S_{\mathrm{m}}=s_{1}+s_{2}+\ldots s_{\mathrm{m}}$ is the inclined (measured) distance and $I_{\mathrm{i}}$ is the inclination of each segment of length $s_{\mathrm{i}}$. This correction was at most $0.6 \mathrm{~m}$ and was not applied to the depths of the temperature or orientation data.

The difference in the $z$ values for each feature, divided by the time interval between surveys, gave the vertical velocity $w$, relative to the topmost point, and positive upwards. The profiles of $w$ for $\mathrm{BHC1}, \mathrm{BHC} 2$, and $\mathrm{BHQ}$ are illustrated in Figures 2(c), 3(c), and 4(c). The $w$ profile is generally subject to an error of $0.07 \mathrm{~m} \mathrm{a}^{-1}$ for $\mathrm{BHCl} 1$ and $\mathrm{BHC} 2$, and $0.02 \mathrm{~m} \mathrm{a}^{-1}$ for BHQ. The open circles in each figure represent the $w$ profile without the correction for vertically which shows how dominant this correction can be in regions of large shear strain. The verticality correction described above (to obtain the solid circles), is probably an over-estimate as the instrument cable takes a less winding path down the bore hole than that given by $S_{\mathrm{m}}$. Thus, the real profile of $w$ lies somewhere between the two sets of points.

\section{FEATURES OF THE ICE FLOW}

\section{BHCl}

A large difference exists between the surface value of $V$ in Figure 2(a) and the measured surface velocity of 

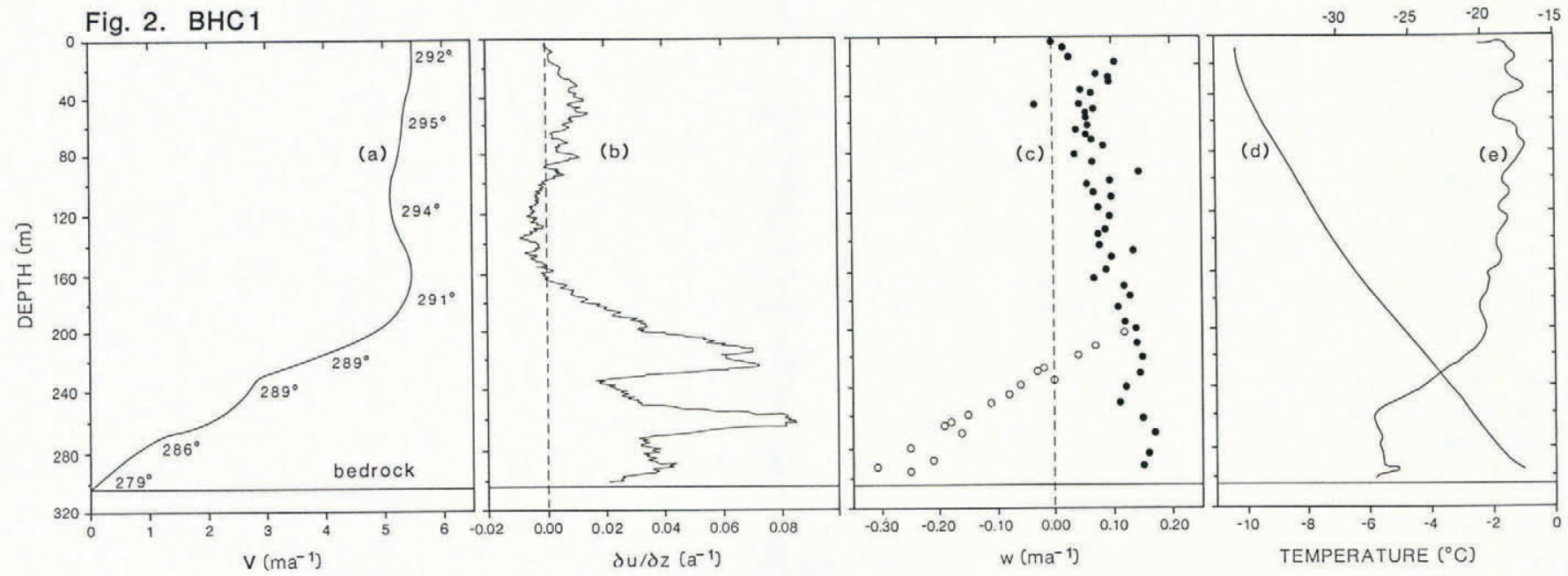

Fig. 3. $\mathrm{BHC2}$
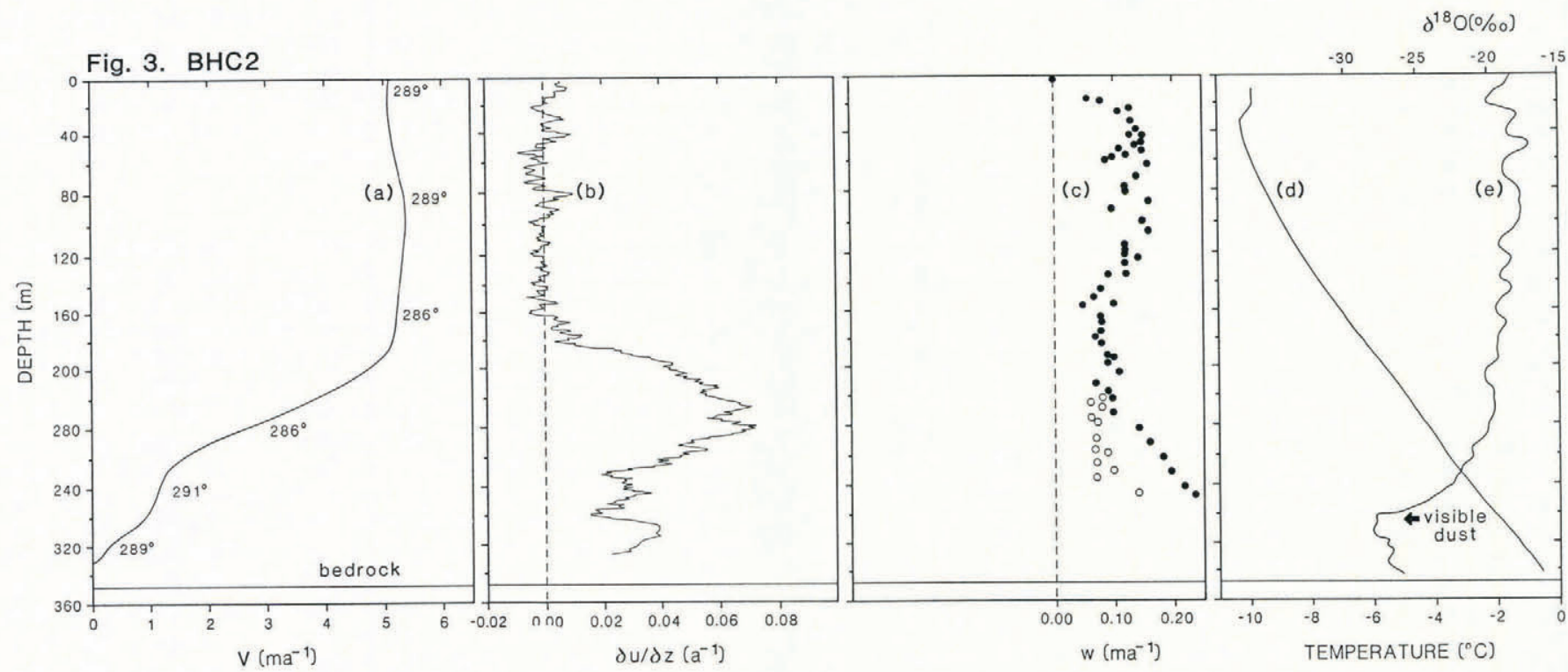

Fig. 4. $B H Q$
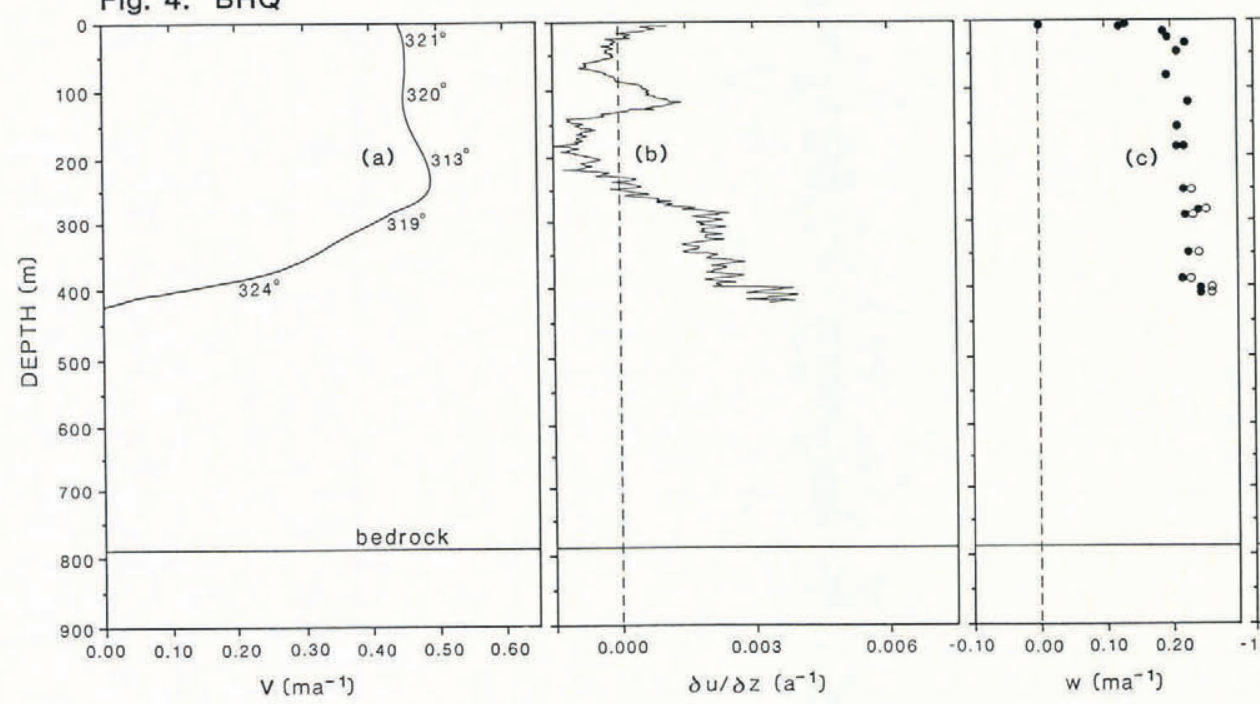

$\partial^{18} \mathrm{O}(\% 0)$

$-30 \quad-20$

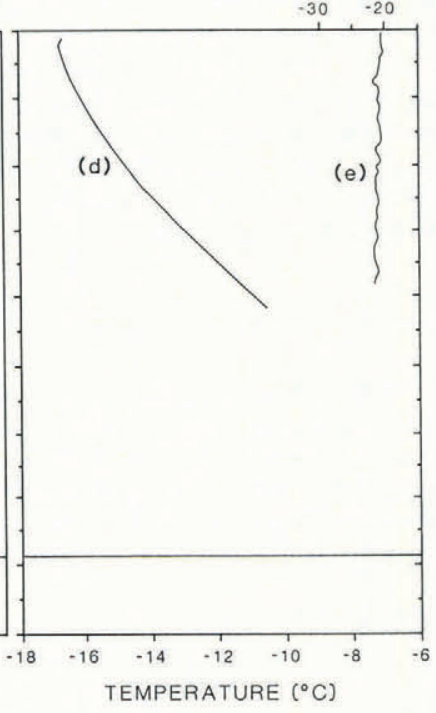

Figs 2, 3, and 4. Results for $\mathrm{BHCl}, \mathrm{BHC2}$, and $\mathrm{BHQ}$, respectively. Within each figure is:

(a) the profile of horizontal velocity $\boldsymbol{V}$ of the ice sheet relative to the bottom of the bore hole. The azimuths of $\boldsymbol{V}$ are written alongside;

(b) the profile of $\partial u / \partial z$ found from $V$ as described in the text;

(c) the vertical velocity $w$, relative to a point fixed in the top of the hole, positive upwards;

(d) the bore-hole temperature profile;

(e) the oxygen-isotope ratio $8^{18} \mathrm{O}$ measured from the ice cores. 
$9.6 \mathrm{~m} \mathrm{a}^{-1}$ at $286^{\circ}$ (Medhurst, unpublished). This difference $\left(4.5 \mathrm{~m} \mathrm{a}^{-1}\right.$ at $\left.277^{\circ}\right)$ is the velocity resulting from deformation and sliding in the $5-10 \mathrm{~m}$ of ice and till between the bottom of the bore hole and bedrock. Basal sliding probably occurs, as extrapolation of the temperature curve in Figure 2(d) to bedrock shows that the ice is at the pressure-melting point of $-0.27^{\circ} \mathrm{C}$ using the coefficient of melting-point depression of Budd and others (1982).

The $\partial u / \partial z$ profile (Fig. 2(b)) differs markedly from the "typical" case for an ice sheet (Paterson, 1981). First, two strong $\partial u / \partial z$ maxima exist in the bottom third of the ice sheet. These are distinct zones where most of the ice deformation occurs. The $\delta^{18} \mathrm{O}$ profile for the $\mathrm{BHCl}$ core (Morgan and McCray, 1985) is given in Figure 2(e) and shows that the ice below $260 \mathrm{~m}$ was deposited during the Wisconsin period. The deeper $\partial u / \partial z$ maximum is located within ice from the later part of the Wisconsin.

The second unusual feature observed in $\mathrm{BHCl}$ is a region of negative $\partial u / \partial z$ values, i.e. an increase of velocity with depth, between 100 and $150 \mathrm{~m}$. These values are well outside errors in the data. Another region of significant positive $\partial u / \partial z$ values is centred on a depth of only $40 \mathrm{~m}$.

The vertical velocity profile for BHCl (Fig. 2(c)) shows contraction in the upper $40 \mathrm{~m}$, attributed mostly to firn compression, followed by a contraction of $0.05-0.10 \mathrm{~m} \mathrm{a}^{-1}$ over the next $160 \mathrm{~m}$. The interpretation of what happens below this depends on how the $w$ data are treated, as discussed earlier, but the data corrected for verticality show that the contraction continues to the hole bottom.

\section{BHC2}

The BHC2 horizontal velocity profile (Fig. 3(a)) shows that the velocity generated in the $5-15 \mathrm{~m}$ between the hole bottom and bedrock accounts for $4.3 \mathrm{~m} \mathrm{a}^{-1}$ at $278^{\circ}$ of the measured surface velocity $\left(9.4 \mathrm{~m} \mathrm{a}^{-1}\right.$ at $285^{\circ}$ (Medhurst, unpublished)). The temperature profile (Fig. 3(d)), extrapolated as for $\mathrm{BHCl}$, shows that the pressure-melting point $\left(-0.23^{\circ} \mathrm{C}\right)$ is reached and thus basal sliding is also expected to contribute largely to this velocity difference.

Features similar to those of $\mathrm{BHCl}$ are seen in the $\partial u / \partial z$ profile of BHC2 (Fig. 3(b)). There are two deformation maxima, although the deeper one in $\mathrm{BHC} 2$ is significantly smaller. It is, however, located in Wisconsin ice as depicted by the $\delta^{18} \mathrm{O}$ profile (Fig. 3(e)). Also shown is a region towards the end of the Wisconsin where visible dust was observed in the $\mathrm{BHC} 2$ core (personal communication from A.P. McCray).

Although the $\mathrm{BHC} 2$ profile displays a region between 50 and $80 \mathrm{~m}$ where $\partial u / \partial z$ becomes negative, similar to the pattern in $\mathrm{BHCl}$, the values are of the same magnitude as the errors and therefore cannot be used with confidence.

The vertical velocity profile (Fig. 3(c)) shows firn compression to a depth of about $40 \mathrm{~m}$. No other significant vertical strain is evident except between 230 and $290 \mathrm{~m}$ where $w$ values, corrected for verticality, show a steep increase indicating possible contraction of the ice sheet at that level. There are no data for the bottom $60 \mathrm{~m}$ of the bore hole.

\section{BHQ}

No significant ice deformation was expected to be seen from the 10 years of measurements in BHQ as it resides in a colder part of Law Dome, where the absolute surface velocity is only $2.4 \mathrm{~m} \mathrm{a}^{-1}$, and the bore hole penetrated only about half the ice thickness. However, Figure 4(a) and (b) shows that $\partial u / \partial z$ increases at $300 \mathrm{~m}$ depth and becomes quite strong by $400 \mathrm{~m}$. This deformation creates a velocity of about $0.4 \mathrm{~m} \mathrm{a}^{-1}$, a significant contribution to the absolute surface velocity. The ice penetrated by BHQ is entirely Holocene, as shown by the $8^{18} \mathrm{O}$ profile of Figure 4(e) (Morgan and McCray, 1985).

Extrapolation of the temperature profile (Fig. 4(d)) shows that ice at bedrock may be close to the melting point, although the occurrence of basal sliding is uncertain. The vertical velocity profile (Fig. 4(c)) shows that firn compression is the only significant vertical strain.

\section{DISCUSSION}

The negative values of $\partial u / \partial z$ observed in $\mathrm{BHCl}$ are an anomalous but not impossible feature of ice-sheet flow. A similar feature was found in Athabasca Glacier by Savage and Paterson (1963), who attributed it to changes in the ice thickness in the $x$-direction, and in the Byrd Station bore hole between 600 and $800 \mathrm{~m}$ by Paterson (1983), who attributed it to inaccuracies in the data.

The two maxima of $\partial u / \partial z$ which were suggested by the results from BHA and BHF have been confirmed in $\mathrm{BHCl}$ and $\mathrm{BHC} 2$. Both maxima occur in ice composed of fine-grained crystals with strong, nearly vertical single-pole $c$-axis fabrics (Xie, 1984). The deeper maximum in each hole resides in Wisconsin ice. Possible causes of these maxima are:

(i) Each maximum corresponds to a local maximum in the shear stress. Russell-Head and Budd (1979) concluded that a shear-stress maximum created by locally irregular bedrock was the cause of the measured $\partial u / \partial z$ maximum in BHF The shear stress would need to have a large horizontal extent to cause the $\partial u / \partial z$ maxima in the $\mathrm{BHCl}$ and $\mathrm{BHC} 2$ bore holes which are positioned quite differently with respect to bedrock features.

(ii) The ice in the regions of $\partial u / \partial z$ maxima deforms more readily due to its impurity content and/or crystal structure. Xie (1984) attributed the deeper $\partial u / \partial z$ maximum to the higher impurity content or smaller crystals of the Wisconsin ice. Similar conclusions have been reached by other authors (Fisher and Koerner, 1986; Dahl-Jensen and Gundestrup, 1987) for the results from Arctic bore-hole sites. The Antarctic ice, however, has a much lower impurity content (Thompson, 1977). A preliminary survey of microparticle content in $\mathrm{BHCl}$ and $\mathrm{BHC} 2$ cores has shown this difference is at least one order of magnitude (personal communication from C.W. Wookey).

(iii) The deeper maximum is caused by the flow properties of the Wisconsin ice and the upper maximum corresponds to a maximum in shear stress. The shear stress could have occurred up-stream and created shear strain and a single-pole fabric which were perpetuated even when the ice flowed to regions of different stress fields. This reasoning could also explain the results from the BHQ core and bore hole. $\mathrm{Li}$ and others (1988) found that strong single-pole fabrics develop towards the bottom of the BHQ core, which is at only half the ice thickness, almost in correlation with the increase of $\partial u / \partial z$ (Fig. 4(b)). This may be due to a "memory" effect of the ice sheet if it passed over the large bedrock rise $12 \mathrm{~km}$ approximately up-stream, as seen in the bedrock profile.

\section{CONCLUSIONS}

The results from the Law Dome bore holes $\mathrm{BHCl}$ and $\mathrm{BHC} 2$ show the presence of two distinct maxima of shear strain-rate in the deeper one-third of the ice sheet, and significant shear strain-rate above with $\partial u / \partial z$ becoming negative in one region. Sliding and/or deformation in the bottom few metres near bedrock account for about $45 \%$ of the absolute surface velocity. The deeper shear strain-rate maximum in each bore hole appears to be related to some property, or a combination of properties, of the Wisconsin ice. The upper maximum may be created up-stream by stresses from bedrock undulations producing a region of high shear strain-rate and a related crystal structure which are then perpetuated as the ice flows down-stream. This may also be the cause of significant shear strain-rate and strong fabric development high above bedrock in the ice sheet at BHQ.

\section{ACKNOWLEDGEMENTS}

J. Wilson and colleagues drilled and surveyed the BHQ core in 1977. A.P. McCray and colleagues drilled and surveyed the $\mathrm{BHCl}$ and $\mathrm{BHC} 2$ cores in 1982. A. Blake headed the winter re-survey party. A special mention must go to E. Wehrle for his expertise with the drilling and survey equipment. I also wish to thank D. Dahl-Jensen and W.S.B. Paterson for their constructive comments on the 
analysis presented in this work, and N.W. Young for assistance with the manuscript.

\section{REFERENCES}

Bird, I.G. and J. Ballantyne. 1971. The design and application of a thermal ice drill. Melbourne, Department of Supply. Antarctic Division. (Tech. Note 3.)

Budd, W.F. and W.I. Morgan. 1977. Isotopes, climate and ice sheet dynamics from core studies on Law Dome, Antarctica. International Association of Hydrological Sciences Publication 118 ((General Assembly of Grenoble 1975 - Isotopes and Impurities in Snow and Ice), 312-321.

Budd, W.F. and R.J.M. Rowden-Rich. 1985. Finite element analysis of two-dimensional longitudinal section flow on Law Dome. ANARE Res. Notes 28, 153-161.

Budd, W.F., T.H. Jacka, D. Jenssen, U. Radok, and N.W. Young. 1982. Derived physical characteristics of the Greenland ice sheet. Parkville, University of Melbourne. Meteorology Department. (Publ. 23.)

Dahl-Jensen, D. and N.S. Gundestrup. 1987. Constitutive properties of ice at Dye 3, Greenland. International Association of Hydrological Sciences Publication 170 (Symposium at Vancouver 1987 - The Physical Basis of Ice Sheet Modelling), 31-43.

Fisher, D.A. and R.M. Koerner. 1986. On the special rheological properties of ancient microparticle-laden Northern Hemisphere ice as derived from bore-hole and core measurements. J. Glaciol., 32(112), 501-510.

Li J., Xie Zichu, and Huang M. 1988. Fabrics of the ice cores from BHQ on Law Dome ice cap, Antarctica. Kexue Tongbao, 33(3), 216-220.

Matsuda, M., G. Wakahama, and W.F. Budd. 1976. Twinning of ice from Antarctic ice sheet. Observations of a-axis orientation associated with diamond c-axis orientation fabric. Low Temp. Sci., Ser. A, 34 , 163-171. [In Japanese with English summary.]

Medhurst, T. Unpublished. Data report, 1983 Casey
Glaciology Program. Australian Antarctic Division. Glaciology Section. Internal Report.

Morgan, V.I. and A.P. McCray. 1985. Enhanced shear zones in ice flow - implications for ice cap modelling and core dating. ANARE Res. Notes 28, 4-9.

Paterson, W.S.B. 1981. The physics of glaciers. Second edition. Oxford, etc., Pergamon Press.

Paterson, W.S.B. 1983. Deformation within polar ice sheets: an analysis of the Byrd Station and Camp Century borehole-tilting measurements. Cold Reg. Sci. Technol., 8(2), 165-179.

Pfitzner, M.L. 1980. The Wilkes Ice Cap Project, 1966. ANARE Sci. Rep. 127.

Raymond, C.F. 1971. Determination of the threedimensional velocity field in a glacier. J. Glaciol., 10(58), 39-53.

Russell-Head, D.S. and W.F. Budd. 1979. Ice-sheet flow properties derived from bore-hole shear measurements combined with ice-core studies. J. Glaciol., 24(90), 117-130.

Savage, J.C. and W.S.B. Paterson. 1963. Borehole measurements in the Athabasca Glacier. J. Geophys. Res., 68(15), 4521-4536.

Thompson, L.G. 1977. Variations in microparticle concentration, size distribution and elemental composition found in Camp Century, Greenland, and Byrd Station, Antarctica, deep ice cores. International Association of Hydrological Sciences Publication 118 (General Assembly of Grenoble 1975 - Isotopes and Impurities in Snow and Ice), 351-364.

Thwaites, R.J., C.J.L. Wilson, and A.P. McCray. 1984. Relationship between bore-hole closure and crystal fabrics in Antarctic ice core from Cape Folger. J. Glaciol., 30(105), 171-179.

Xie Zichu. 1984. Ice formation and structure on Law Dome, Antarctica. Ann. Glaciol., 6, 150-153.

Young, N.W., Xie Zichu, and Qin Dahe. 1985. Multilayer crystallographic structure of Law Dome from ice core analysis. ANARE Res. Notes 28, 18-24. 